\title{
BENTUK KONKRET METODE BACA -TULIS BERBASIS BAHASA IBU (CONTOH KASUS BAHASA LABOYA)
}

\section{CONCRETE FORM OF READING-WRITING METHOD BASED ON MOTHER TONGUE (CASE STUDY IN LABOYA LANGUAGE)}

\author{
Muh Akbar Kurniawan ${ }^{1 *}$, Abdurrahman Shaleh Reliubun ${ }^{2}$, Martina Fandasari ${ }^{3}$ \\ Pendidikan Bahasa Indonesia, Universitas Ma'arif Nahdlatul Ulama Kebumen, \\ Indonesia ${ }^{1}$, Bahasa Inggris, STIH Umel Mandiri Tual, Indonesia ${ }^{2}$, Sosiologi, \\ Universitas Terbuka, Indonesia ${ }^{3}$ \\ muhakbarkurniawan89@gmail.com $^{1}$, reli.abdurrahman@gmail.com ${ }^{2}$, \\ martina.fanda94@gmail.com ${ }^{3}$ \\ *penulis korespondensi
}

\begin{tabular}{ll}
\hline Info Artikel & ABSTRAK \\
\hline Sejarah artikel: & Artikel ini adalah sebuah refleksi pengalaman penulis selama menjadi \\
Diterima: & fasilitator pendidikan alternatif di Kampung Adat Sodan, Sumba Barat. \\
24 Juli 2021 & Penulis melihat bahwa kekayaan linguistik di Sumba Barat tidak menjamin \\
Direvisi: & adanya penggunaan bahasa pengantar dan materi ajar berbahasa ibu, \\
12 Desember 2021 & khususnya bahasa Laboya. Sekolah formal cenderung menggunakan materi \\
Disetujui: & ajar yang bersifat asing, terutama di kelas awal sekolah dasar. Hal ini yang \\
14 Januari 2022 & menyebabkan tingginya angka buta huruf di Sumba Barat, adapun faktor \\
& lain, yakni kekerasan budaya seperti, harus meninggalkan identitas marapu- \\
Kata kunci: & nya sebagai kepercayaan lokal jika ingin bersekolah formal. Hasil refleksi \\
materi ajar, baca tulis,, & tersebut yang melatari penulis menyusun metode baca-tulis berbasis bahasa \\
bahasa laboya & Laboya. Data penelitian kualitatif ini diperoleh dengan wawancara etnografi \\
& dan observasi-aplikasi pengetahuan dalam sebuah praksis. Data yang \\
& diperoleh dalam bentuk data kebahasaan berupa kosakata bahasa Laboya \\
& kemudian diinput ke dalam FieldWorks, sebuah perangkat lunak \\
dokumentasi data linguistik dan budaya. Data kemudian diklasifikasi & berdasarkan pada tipe struktur silabisnya. Hasil penelitian menemukan \\
& terdapat 11 bentuk silabis.
\end{tabular}

\begin{tabular}{ll}
\hline Article Info & ABSTRACT \\
\hline Article history: & This article reflects authors experience as alternative education facilitators \\
Received: & in Kampung Adat Sodan, Sumba Barat. The authors observed that linguistic \\
24 July 2021 & richness in Sumba Barat does not guarantee the use of instruction language \\
Revised: & and teaching materials in mother tongue, especially Laboya language. \\
12 December 2021 & Formal school tends to use foreign teaching materials, especially in the early \\
Accepted: & levels of primary school. This phenomenon has led to the high illiteracy rate \\
14 January 2022 & in Sumba Barat. Another factor is cultural violence, as in the necessity to \\
& leave the Marapu identity, as a local belief, to enroll in formal school. This \\
Keyword: & reflection encouraged the authors to compose Laboyan-based reading and \\
teaching materials, & writing method. Qualitative data was obtained through ethnographic \\
reading and writing, & interview and observation-application in praxis. The obtained data in the \\
laboya language & form of Laboya lexicons were inputted to FieldWorks, a documentation \\
& software for linguistic data and culture. The data was classified based on \\
& syllabic structure types. The study found 11 syllabic structures.
\end{tabular}




\section{PENDAHULUAN}

Membaca dan menulis selalu dijadikan tolok ukur kemampuan individu terhadap literasi dasar. Sebagaimana dikemukakan oleh Saryono, dkk (2017) membaca dan menulis merupakan satu dari enam kemampuan literasi yang harus dikuasai. Sejarah mencatat bahwa membaca dan menulis merupakan kecakapan yang paling pertama ada dalam sejarah literasi umat manusia. Jika dilihat dari sisi fungsinya kecakapan ini memiliki kegunaan dan peran sentral dalam rutinitas harian manusia.

Terdapat beragam istilah terkait dengan literasi, jamaknya di Indonesia disebut dengan melek huruf jika individu atau suatu kelompok mampu membaca dan menulis, sementara buta huruf merupakan oposisi istilah yang disematkan kepada individu dan kelompok jika kemampuan tersebut tidak dimiliki. Dalam skala yang lebih luas kecakapan ini dimaknai sebagai alat untuk memahami dan mengatasi berbagai persoalan hidup. Seperti yang diungkapkan Dewi dan Antosa (2020) bahwa keterampilan literasi sangat penting karena memenuhi tuntutan globalisasi dan pengembangan kehidupan pribadi, serta sosial mereka. Lebih lanjut, Ghanggo Ate (2019) menjelaskan, literasi tidak sekadar keterampilan membaca dan menulis, tetapi melampaui hal tersebut, literasi sanggup mengurai perseolaan hidup, seperti kemiskinan, kesehatan, dan kehidupan sosial.

Rizaty mencatat sebagaimana yang dilansir Data Books (2021) angka buta huruf sepuluh tahun terakhir mengalami penurunan, khususnya di kelompok usia 10 tahun ke atas. Badan Pusat Statistik mencatat pada tahun 2011 angka buta huruf di Indonesia sebesar $6,44 \%$, kemudian pada tahun 2015 mengalami penurunan hingga $4,27 \%$ setahun kemudian mengalami kenaikan menjadi 4,62 \%, tetapi pada tahun 2020 kembali menurun menjadi $3,62 \%$.

Penurunan angka buta huruf di rentang tahun 2011-2020 bukan berarti mencerminkan peningkatan taraf atau mutu literasi di Indonesia. Hal tersebut hanyalah gambaran umum yang tidak menjelaskan secara rinci dan mendalam perihal kondisi literasi masing-masing daerah di nusantara. Beberapa daerah yang yang ditempati oleh masyarakat adat misalnya tidak terlalu disoroti kondisi literasinya.

Sejatinya yang membuat adanya ketimpangan di tubuh pendidikan kita adalah karena tidak adanya pendidikan khusus yang inklusif bagi masyarakat adat. Yogaswara dan Zamjani (2019) menjelaskan bahwa pendidikan inklusif pendidikan yang menerima semua anak apapun kondisinya, serta segala hal yang tersemat padanya, seperti kondisi fisik, kepercayaan, bahasa, budaya, dan sebagainya. UNESCO menerangkan bahwa Pendidikan inklusif sebagai proses yang berfokus pada kebutuhan yang beragam dari semua anak melalui partisipasi aktif dalam pembelajaran, budaya dan masyarakat dengan mengurangi tindakan eksklusif dalam Pendidikan (UNESCO and Ministry Education Science Spain, 1994).

Hadirnya pendidikan khusus yang dapat mengakomodasi kepentingan masyarakat adat, masih jauh dari harapan. Sebab, Upacara adat, kondisi sosial budaya, kepercayaan lokal, dan geografis selalu dijadikan sebagai tumpuan kesalahan atau alasan penghambat dari kemajuan (Inovasi, 2019).

Berdasarkan pengamatan penulis ketika menjadi fasilitator pendidikan 
alternatif di beberapa daerah, bukan karena rendahnya kemampuan masyarakat adat dalam berbahasa Indonesia atau karena ketertinggalan mereka terhadap perkembangan zaman dan teknologi, tetapi karena kekerasan budaya dalam memperoleh hak pendidikannya.

Anak-anak Suku Kajang di Sulawesi Selatan untuk mengakses dan mendapatkan hak pendidikannya harus meninggalkan bahasa Konjo sebagai bahasa ibunya, sebab sekolah formal tidak menggunakannya sebagai bahasa pengantar atau muatan lokal. Di Hutan Bukit Duabelas Jambi Orang Rimba jika ingin ke sekolah formal mereka tidak hanya meninggalkan bahasa Rimba sebagai bahasa kesehariannya, tetapi juga hutan sebagai tempat tinggal mereka. Sementara di Sumba Barat khususnya anak-anak Kampung Adat Sodan yang menuturkan bahasa Laboya, selain bahasa mereka tidak di ajarkan di sekolah formal mereka juga harus meninggalkan identitas marapunya sebagai kepercayaan lokal jika ingin merasakan pendidikan formal.

Pulau Sumba menempati peringkat teratas sebagai daerah tertinggi angka buta hurufnya di Provinsi Nusa Tenggara Timur. Dari empat kabupaten yang ada di Pulau Sumba, Sumba Barat menempati peringkat kedua tertinggi buta hurufnya setelah Sumba Barat Daya dengan presentase $15,02 \%$ untuk usia 15-59 tahun dan 19,21\% untuk usia di atas 15 tahun karena angka ini mewakili angka di atas 4\% untuk keseleluruhan wilayah Nusa Tenggara Timur maka dikategorikan sebagai zona merah (Kemendikbud, 2019).

Tingginya angka buta huruf di Sumba, khususnya di Sumba Barat sejatinya bukan karena kualitas guru atau fasilitas di sekolah formal tetapi tidak hadirnya metode pembelajaran literasi yang tepat, dalam hal ini metode baca tulis berbasis bahasa ibu. Hal ini sejalan dengan apa yang diterangkan Hanemann (2005) minimnya pendidikan berbahasa ibu berkontribusi terhadap rendahnya angka melek huruf pada masyarakat adat, dibandingkan dengan rata-rata nasional. Contoh kecil terlihat di Kecamatan Lamboya dan ini mencerminkan seluruh Pulau Sumba dan Nusa Tenggara Timur, di mana kekayaan linguistik tidak menjamin adanya penggunaan bahasa pengantar dan materi ajar berbahasa ibu. Bahasa pengantar dan materi ajar berbahasa Laboya/Lamboya sulit dijumpai di sekolah formal, begitu pun pada lingkup muatan lokal bahasa ini tidak pernah diajarakan. Bahasa Laboya merupakan bahasa yang dituturkan di Kabu Karudi pusat Kecamatan Lamboya (Aritonang, dkk 2002). Verdizade (2019) menambahkan bahwa bahasa Laboya berada di antara komunitas linguistik Gaura yang berada di sebelah barat, Wejewa di barat laut, dan Rua sebagai wilayah pesisir di sebelah tenggara. Bahasa ini mayoritas dituturkan di wilayah Kecamatan Lamboya dan Laboya barat di mana jumlah penduduknya pada tahun 2015 mencapai 31.359 orang, namun angka ini tidak dapat mencerminkan jumlah pasti penutur bahasa tersebut. Isolek laboya dikategorikan sebagai suatu bahasa, di mana presentase perbedaan dengan bahasa sekitarnya seperti Wewewa dan Wanukaka di atas $81 \%$ (Badan Pengembangan dan Pembinaan Bahasa, 2017).

Anak-anak yang menuturkan bahasa ibu mereka tetapi berbeda dari bahasa nasional sering dirugikan oleh sistem pendidikan. Padahal anak-anak yang berbahasa ibu secara umum kemampuan akademiknya lebih baik 
ketimbang anak-anak yang hanya menuturkan bahasa nasional (ACDP Indonesia, 2014). Hal senada diungkapkan, Küper dan Lopez (2000) Penelitian tentang pendidikan dwibahasa antarbudaya yang dilakukan di negara-negara Amerika Latin memperlihatkan bahwa peserta didik yang mengawali belajar dengan bahasa ibu memperoleh nilai lebih baik di bahasa kedua dan juga meningkatkan kepercayaan diri mereka.

Anindita, dkk

menerangkan, penggunaan bahasa ibu ketika mengajarkan literasi dasar merupakan suatu permulaan yang tepat dalam pemertahanan bahasa dan menumbuhkan kebanggaan anak terhadap identitasnya. Terkait pemertahanan bahasa, Ibda (2017) menjelaskan, pemertahanan yang dimaksud tidak sekadar penggunaannya saja dalam hal proses pembelajaran, melainkan harus terstruktur rapi dan dirancang secara ilmiah karena bahasa ibu memiliki keunikan, oleh karena itu harus mengakomodasi upaya pemertahanan sebagai bahasa pertama bagi peserta didik. Selain peningkatan capaian akademik, keperyaan diri, dan kebanggan identitas, serta pemertahanan bahasa ibu pada masyarakat adat, ada hal yang tidak kalah pentingnya terkait bahasa ibu, sebagaiaman yang dijelaskan Mahsun (2001) bahasa ibu tidak hanya berperan sebagai sarana komunikasi internal, tetapi juga sebagai mediator pembangunan, pengembangan masyarakat, dan warisan budaya di mana setiap masyarakat yang menuturkan bahasa tersebut, oleh karena itu penggunaan bahasa ibu dalam pendidikan di kelas awal sekolah dasar atau di usia 6-8 tahun suatu keharusan.
Anak-anak di Kampung Adat Sodan mewarisi berbagai pengetahuan tradisional dari orang tua mereka, bukan dari guru mereka di sekolah formal. Istilah seperti, tingu yayu 'ritual tarik kayu', wulla paddu 'bulan pantang', mananu 'menenun', pahalana 'ritual adu lempar lembing', dan lain-lain. Tentu pengetahuan seperti itu dalam proses transfernya, bahasa Laboya berperan sangat besar. Hanya dengan bahasa Laboya mereka dapat memahami identitas budayanya dengan baik. Begitu pun sebaliknya adat hanya diekspresikan dan diartikulasikan dalam bahasa Laboya. Hal ini yang kemudian melatari penulis dalam meneliti dan menyusun metode baca-tulis berbasis bahasa Laboya, yang materinya bersumber dari budaya dan semua aspek kehidupan mereka. Karena tujuan dari metode baca-tulis berbasis bahasa Laboya adalah selain memudahkan mereka dalam memahami materi literasi dasar, ada hal yang lebih penting, yakni menumbuhkan kebanggan akan identitas mereka sebagai Orang Sodan, dengan begitu pelestarian bahasa dan budaya Laboya (Sodan) dapat terwujud.

\section{METODE}

Artikel ini menggunakan pendekatan penelitian kualitatif. Jika disintesiskan dari beragam defenisi yang ada penelitian ini memiliki tujuan untuk memahami fenomena apa yang dialami oleh subjek penelitian secara holistik dan dengan cara deskripsi dalam bentuk kata-kata dan bahasa (Jane Richie dalam Moleong, 2017). Data diperoleh dengan menerapkan dua teknik, yakni: (1) wawancara etnografi sebuah teknik wawancara yang boleh juga disebut sebagai percakapan persahabatan. Sebelum penulis 
melakukan penelitian, terlebih dahulu menjalin relasi yang dekat dengan para informan kurang lebih setahun tinggal di Kampung Adat Sodan, sembari mengamati rutinitas harian, penggunaan bahasa Laboya dan kaitan beberapa kosakata/leksikon terhadap sistem sosial dan budaya mereka. Penulis melakukan wawancara secara terbuka dan mendalam terhadap empat orang rato 'sesepuh adat', latar belakang informan yang jarang melakukan kontak bahasa dengan penutur bahasa Indonesia, yang mendasari pemilihan informan tersebut. Penulis menggunakan tiga bentuk pertanyaan entografi yang terdiri dari: (a) pertanyaan deskriptif, misalnya dapatkah anda menjelaskan makna dari keduabelas nama bulan tradisional Orang Sodan?; (b) pertanyaan struktural, misalnya dalam bahasa Laboya, lembing yang digunakan pada saat ritual pahalana disebut?; (c) pertanyaan yang kontras, misalnya bagaimana cara menyebutkan kaboko 'ikan' dan kaboko 'piton' dalam bahasa Laboya?. (2) observasi dan aplikasi pengetahuan dalam sebuah praksis. Penulis melibatkan diri dalam beberapa aktivitas yang dilakukan oleh Orang Sodan, misalnya rayina umma mantoko 'membangun rumah adat', di tengah aktivitas tersebut, penulis menanyakan beberapa hal yang berkaitan dengan rumah adat. Proses ini dilakukan untuk melengkapi data primer yang didapatkan pada saat wawancara etnografi. Data bahasa yang terkumpul kemudian diinput satu per satu ke dalam perangkat lunak bernama FieldWorks Language Explore, kemudian dilengkapi dengan kelas kata dan artinya. Selanjutnya kosakata yang telah terinventarisasi, diklasifikasikan berdasarkan tipe struktur silabisnya. Tipe silabis ini disusun dari struktur yang sederhana, sedang, hingga yang rumit. Hal tersebut dilakukan agar modul baca-tulis tesebut dalam penggunaannya, memudahakan guru dan peserta didik.

\section{HASIL DAN PEMBAHASAN}

Metode baca tulis berbasis bahasa ibu tidak hanya berupa susunan materi yang diambil dari kosakata lokal dengan penggunaan bahasa ibu sebagai pengantarnya, atau setidaknya menggunakan dialek setempat, tetapi perlu juga membangun kedekatan emosional dengan peserta didik dan menggunakan teknik mengajar, seperti: (1) guru tunjuk-peserta didik sebut, digunakan untuk mempermudah peserta didik belajar membaca; (2) guru sebut-peserta didik tunjuk, digunakan untuk mempermudah peserta didik belajar menulis; (3) guru tulis-peserta didik sebut, digunakan untuk mempermudah peserta didik belajar membaca tanpa contekan; (4) guru sebut-peserta didik tulis, digunakan untuk mempermudah peserta didik belajar menulis tanpa contekan. Teknik tersebut perlu diaplikasikan baik ketika mengenalkan huruf maupun ketika mengajarkan membaca atau melafalkan kata.

Sebelum ke tahap pelajaran membaca, peserta didik terlebih dahulu diajarkan pengenalan huruf. Penting diketahui bahwa tahap ini sebaiknya memperhatikan kekhasan fonetis bahasa ibu dari peserta didik tersebut. Selain itu, penggunaan contoh huruf yang berasal dari lingkungan sekitar juga penting karena tidak hanya memudahkan peserta didik dalam mengenal huruf sebelum ke tahap membaca kata demi kata hingga kalimat. Lebih dari itu ada tujuan penting lainnya, yakni menumbuhkan kebangaan identitas sebagai Orang 
Sodan dan melestarikan bahasa Laboya. Misalny huruh /A/ (kapital) menyerupai toko umma 'menara rumah', tentu persepsi peserta didik tidak hanya sampai pada menara rumah tetapi berkembang ke arah yang lebih luas terkait dengan aktivitas atau pengetahuan yang berkaiatan dengan atap rumah adat mereka, seperti kakdu kari 'kayu yang menyerupai tanduk kerbau, simbol suci dalam kepercayaan mereka' atau /I/ seperti karikge 'lembing kayu'. Pada contoh ini pun mereka akan membayangkan dan memikirkan tentang beberapa hal mengenai ritual pahalana 'adu lembing kayu', seperti mara parona 'gugusan batu tempat berdoa ketika menjelang pahalana'. Jadi mengajarkan huruf dengan penjelasan yang sesuai dengan konteks bahasa dan budaya mereka, di tahap ini saja peserta didik sudah banyak mempelajari budayanya, apatah lagi jika sampai ke tahap melafalkan kata dan seterusnya.

Adapun kasus pada bahasa Laboya terdapat dua fonem yang dibaca dan ditulis samar yakni /h/ dan /s/ bagi penutur bahasa Laboya saat menyebut dan menulis huruf /s/, tidak menjadi masalah jika diganti dengan huruf /h/ atau sebaliknya, misalnya ketika mereka menyebut wehola 'nama klan' sebagian menyebutnya wesola, hal serupa juga dijumpai pada kata lihu 'ikatan padi/pocongan', kadang-kadang disebut lisu. Berbeda jika kasusnya pada bahasa Indonesia kerancuan tersebut harus diperbaikai.

Selain itu, bahasa Laboya memiliki kecendrungan struktur KVKV, tipe silabis atau suku kata yang paling umum dijumpai $\mathrm{KV}$ meskipun tipe $\mathrm{V}$ dan KVK juga sering dijumpai pada kosakata tertentu. Pelajaran membaca dengan menggunakan kosakata bahasa Laboya dibagai ke dalam beberapa pola dan tingkatan berdasarkan kerumitan tiap tipe struktur silabisnya. Berikut bentuk materi ajar yang di maksud.

\section{$\mathbf{K V}+\mathbf{K V}$}

Merupakan tipe struktur pertama dengan dua silabel.

\begin{tabular}{|l|l|}
\hline B- & Arti \\
\hline BA-HA & Mencuci \\
\hline BA-LE & Bahu \\
\hline BA-RA & Menyembah \\
\hline BA-NI & Marah \\
\hline G- & Arti \\
\hline GE-GE & Laba-laba \\
\hline GA-KA & Gagak \\
\hline H- & Arti \\
\hline HE-LA & Pelana Kuda \\
\hline HI-TA & Pedas \\
\hline J- & Arti \\
\hline JA-RA & Kuda \\
\hline JO-RO & Cantik \\
\hline K- & Arti \\
\hline KI-KU & Ekor \\
\hline KA-RI & Kerbau \\
\hline KE-DU & Kera \\
\hline KE-RU & Parutan kelapa \\
\hline KA-BA & Benang \\
\hline N- & Arti \\
\hline NA-MU & Ingat \\
\hline NA-PU & Kebun kelapa \\
\hline NA-MA & Tante \\
\hline NA-BU & Tombak \\
\hline NI-YO & Buah kelapa \\
\hline P- & Arti \\
\hline PA-BA & Sawah \\
\hline PE-GA & Piring \\
\hline PA-RE & Padi \\
\hline R- & Arti \\
\hline RA-TA & Seribu \\
\hline RA-TO & Sesepuh adat \\
\hline RE-GA & \\
\hline
\end{tabular}

Pelajaran membaca dimulai dengan tipe struktur pertama. Sebelum mengajarkannya, seorang guru pelu menekankan pada peserta didik bahwa semua huruf tidak dapat dibaca sekali ucap bila tidak dipasangkan antara huruf konsonan dengan huruf vokal. Hal tersebut akan menjadi pedoman selama pembelajaran membaca kata. 
Selanjutnya, mulai mengajarkan cara menggabungkan kata yang memiliki arti atau makna dalam bahasa Laboya. Tentu tidak sekadar memiliki arti tetapi juga makna dan nilai budaya lokal mereka. Jika tidak dapat menampilkan secara keseluruhan leksikon yang berkaitan pada budaya mereka, setidaknya ada beberapa leksikon yang mewakilinya.

Beberapa contoh pada tipe struktur pertama ditemukan leksikon yang bertalian dengan budaya Orang Sodan, seperti bara memiliki arti menyembah atau pemujaan kepada arwah-arwah leluhur, praktik seperti ini tidak asing pada peserta didik karena kerap mereka jumpai di berbagai ritual atau aktivitas, misalnya pernikahan, pembangunan rumah adat, atau ketika hendak memulai suatu kegiatan. Kemudian, jara 'kuda'. Kuda bagi Orang Sumba pada umumnya tidak hanya sekadar alat transportasi, tetapi juga berperan penting dalam kehidupan dan budaya, ketika membaca atau melafalkan kata jara secara tidak langsung dibenak peserta didik akan muncul istilah pahalana karena kuda menjadi bagian dari ritual tersebut. Berikutnya, kata kari 'kerbu', bagi Orang Sumba kerbau memiliki posisi yang sama dalam kehidupan, baik sebulum kematian maupun setelah kematian. Peserta didik akan cepat mengenali kata ini beserta fungsinya, mereka akan membayangkan ketika kerbau dimanfaatkan untuk membajak sawah dan dikorbankan untuk arwah leluhur ketika upacara penguburan. Terakhir, kata rato 'sesepuh adat', kata ini juga bagi peserta didik sangat bermakna, sebab umumnya mereka memiliki bapak atau kakek seorang rato. Tetapi tidak sampai di situ saja mereka kemudian mengembangkan pemahamnnya, bahwa rato bukan sekadar sesepuh adat yang dituakan namun sosok yang memiliki pengetahuan yang luas dan wawasan terkait adat-istiadat, religiositas terhadap kepercayaan marapu, dan benteng terakhir yang menjaga kelangsungan budaya sumba.

\section{$\mathbf{V}+\mathbf{K V}$}

Merupakan tipe struktur kedua dengan dua silabel.

\begin{tabular}{|l|l|}
\hline A- & Arti \\
\hline A-LU & Penumbuk padi \\
\hline A-MA & Bapak \\
\hline A-LI & Adik \\
\hline A-NA & Anak \\
\hline A-WA & Sembarang \\
\hline A-TA & Orang \\
\hline A-GU & Hibur \\
\hline E- & Arti \\
\hline E-JU & Kedondong \\
\hline E-PU & Gempa bumi \\
\hline E-RA & Engklek \\
\hline E-NU & Minum \\
\hline U- & Arti \\
\hline U-LU & Gagang parang \\
\hline U-TU & Untung \\
\hline U-RA & Hujan \\
\hline O- & Arti \\
\hline O-MA & Kebun \\
\hline O-RO & Bekas \\
\hline O-LE & Teman \\
\hline & \\
\hline
\end{tabular}

Tipe ini digunakan pada pelajaran membaca kata dengan sekali ucap. Contoh kata pada tipe ini terdiri dari tiga fonem yang dibaca sekaligus. Seorang guru perlu menekankan juga ketika mengajarkan kata-kata tersebut bahwa vokal menjadi penanda ciri artikulasi di akhir katanya. Ini jamak dijumpai pada kosakata bahasa Laboya. Meskipun secara signifikan tidak ditemukan leksikon yang secara langsung bertalian dengan budaya Orang Sodan, setidaknya dijumpai beberapa contoh yang dapat memancing ekspresi dan deskripsi peserta didik terhadap leksikon 
tersebut, seperti era 'engklek' sebuah permainan tradisional yang juga sering dimainkan oleh mereka. Kemudian, ada kata ulu 'gagang parang' ketika membaca kata tersebut peserta didik akan membayangkan beragam bentuk gagang parang, bahan yang digunakan, dan nilai ekonomis dari masing-masing gagang tersebut.

\section{KVK+ KV}

Merupakan tipe struktur ketiga dengan dua silabel, pada bagian ini peserta didik diajari membaca dengan sistem gabungan bentuk konsonan dengan vokal, kemudian konsonan dengan konsonan, dan vokal.

\begin{tabular}{|l|l|}
\hline -D+.. & Arti \\
\hline BAD-LA & Senjata \\
\hline HAD-DE & Bersandar \\
\hline KUD-DO & Lutut \\
\hline HAD-KA & Sodet kayu \\
\hline -G+.. & Arti \\
\hline BAG-GA & Anjing \\
\hline BOG-TA & Kenyang \\
\hline TEG-LA & Kurus \\
\hline -H+.. & Arti \\
\hline BAH-HI & Besi \\
\hline BIH-HA & Pemali \\
\hline DUH-KA & Tusuk \\
\hline -J+.. & Arti \\
\hline BAJ-LA & Bunuh \\
\hline TUJ-JA & Serupa \\
\hline
\end{tabular}

Dalam mengajarkan tipe ini perlu ditekankan bahwa konsonan yang berada di depan dibaca tunggal apabila di depannya terdapat kluster atau dua konsonan yang memungkinkan diucapkan sekaligus, pada kasus ini diucapkan secara terpisah agar memudahkan mereka membacanya. Pada tipe ini hanya ditemukan dua kata yang khas meskipun secara signifikan tidak ditemukan leksikon yang secara langsung bertalian dengan budaya Orang Sodan, setidaknya dijumpai beberapa contoh yang dapat memunculkan ekspresi dan deskripsi terkait leksikon tersebut. Adapun yang dimaksud, seperti bagga 'anjing' bagi Orang Sodan anjing tidak hanya sekadar sebagai penjaga kebun atau anjing pemburu, selain dari itu anjing merupakan hewan yang dijadikan sebagai persembahan pada ritual tertentu, misalnya ketika menarik tiang kayu di hutan untuk kepentingan membangun rumah adat begitu pun pada upacara kematian. Beberapa klan dan sesepuh adat juga memaknai anjing sebagai hewan yang pantang untuk dikonsumsi karena adat mengaturnya. Selanjutnya, kata bihha 'pemali' bagi peserta didik kata tersebut mengandung makna yang mendalam karena mereka akan mengingat dan membayangkan beragam benda dan tempat yang pantang untuk dipegang dan dipijak yang tersebar di sekitar kampung adat mereka.

$\mathbf{K V}+\mathbf{K V}+\mathbf{K V} \ldots$

Merupakan tipe struktur keempat dengan tiga silabel hingga empat silabel.

\begin{tabular}{|l|l|}
\hline -A & Arti \\
\hline BU-BA-TA & Rokok \\
\hline DE-KE-NA & Menginjak \\
\hline HO-DE-KA & Sendok \\
\hline -U & Arti \\
\hline KA-LA-KU & Ranting \\
\hline MA-RA-PU & $\begin{array}{l}\text { Kepercayaan lokal } \\
\text { Orang Sumba }\end{array}$ \\
\hline -E & Arti \\
\hline KA-ME-ME & Kambing \\
\hline TA-LE-DE & Mengapung \\
\hline DU-KA-GE & Habis \\
\hline -O & Arti \\
\hline KA-TO-PO & Parang \\
\hline KA-DO-DO & Nasi \\
\hline KA-BO-KO & Ikan \\
\hline -I & Arti \\
\hline WO-LE-TA-DI & Berjalan keliling \\
\hline MA-RA-PA-TI & Nama klan \\
\hline -A & Arti \\
\hline KA-BE-BA-KA & Kupu-kupu \\
\hline MA-NA-WA-RA & Rindu \\
\hline
\end{tabular}




\begin{abstract}
KA-LA-WA-RA Sakit

Tipe ini menekankan pada artikulasi bunyi vokal. Teknik mengajarkannya dengan cara membaca masing-masing dua suku kata pada tipe struktur tersebut. Penting juga mengelompokkan kata yang memiliki akhiran vokal yang serupa sembari menunjukkan pola artikulasinya. Pada tipe ini ditemukan tiga leksikon yang bertalian dengan budaya Orang Sodan, yakni marapu 'Kepercayaan lokal Orang Sumba'. Ketika peserta didik membaca kata marapu secara otomatis akan memunculkan memori kolektif mereka terkait kata tersebut. Bahwa marapu merupakan sistem kepercayaan lokal yang bersifat animistis yang berbasis pada pemujaan terhadap arwah-arwah leluhur, selain itu marapu juga merupakan identitas Orang Sumba. Selanjutnya, katopo 'parang' kata tersebut juga akan memunculkan sebuah ekspresi dan deskripsi bahwa katopo bagi Orang Sumba terutama laki-laki merupakan simbol kedewasaan, kebijaksanaan, dan kemenangan umumnya digunakan untuk hal-hal yang berguna bukan untuk melukai apalagi membunuh. Kemudian marapati 'nama salah satu klan' kata ini serupa dengan rato juga akan memunculkan memori kolektif utamanya bagi peserta didik yang merupakan bagian dari klan tersebut. Bahwa marapati merupakan salah satu klan besar dan bagian dari sembilan klan yang ada di Kampung Adat Sodan. Klan ini memiliki rumah adat utama yang disebut dengan uma lia.
\end{abstract}

\section{$\mathbf{V K}+\mathbf{K V}+\mathbf{K V}$}

Merupakan tipe struktur kelima, dengan tiga silabel. Pada tipe ini perlu ditekankan kepada peserta didik bahwa jika setelah vokal terdapat dua konsonan, maka konsonan tersebut harus dibagi dua, di mana konsonan yang paling dekat dengan vokal penyebutannnya digabung.

\begin{tabular}{|l|l|}
\hline A- & Arti \\
\hline AM-MA-HA & Uang \\
\hline AM-MO-HA & Memasukkan \\
\hline U- & Arti \\
\hline UL-LA-NA & Bekerja \\
\hline
\end{tabular}

Pada tipe ini tidak banyak ditemukan contoh leksikon dalam bahasa Laboya begitu pun yang bertalian dengan budaya Orang Sodan, tetapi ditemukan satu kata yang dapat memunculkan ekspresi dan deskripsi terkait kata tersebut, yakni ullana 'bekerja' bahwa dalam bekerja Orang Sodan selalu mengedepankan prinsip gotong royong tanpa mengharapkan balas budi, dalam istilah mereka disebut hawadda.

\section{$\mathbf{V K}+\mathbf{K V}$}

Merupakan tipe struktur keenam dengan dua silabel.

\begin{tabular}{|l|l|}
\hline A- & Arti \\
\hline AN-NI & Enam \\
\hline AM-MU & Tutup mulut \\
\hline AL-LI & Terlalu \\
\hline AT-TU & Pergi \\
\hline U- & Arti \\
\hline UP-PO & Mangga \\
\hline UM-MA & Rumah \\
\hline UT-TA & Liar \\
\hline UR-RA & Hujan \\
\hline
\end{tabular}

Ketika mengajarkan tipe ini perlu diingatkan bahwa cara membacanya serupa dengan tipe struktur kelima, hanya saja pada tipe ini setelah menyebut vokal dan dua konsonan diakhiri dengan vokal. Pada tipe ini tidak banyak ditemukan contoh leksikon dalam bahasa Laboya begitu pun yang bertalian dengan budaya Orang Sodan, tetapi ditemukan satu 
kata yang dapat memunculkan ekspresi dan deskripsi peserta didik terhadap leksikon tersebut, yakni umma atau uma 'rumah'. Bagi Orang Sodan rumah memiliki nilai filosofis, mereka memaknai rumah sebagi mikrokosmos yang berfungsi bukan hanya sebagai tempat berteduh, tetapi sebagai tempat manusia berhubungan dengan tuhan, dengan sesama manusia, dan dengan sesama makhluk hidup lainnya.

\section{$\mathbf{K V K}+\mathbf{K V}+\mathbf{K V}$}

Merupakan tipe struktur ketujuh dengan tiga silabel.

\begin{tabular}{|l|l|}
\hline B- & Arti \\
\hline BAB-BO-RA & Mengelabuhi \\
\hline BAL-LE-KA & Lebar \\
\hline G- & Arti \\
\hline GAL-LA-RA & Luas \\
\hline K- & Arti \\
\hline KAD-DA-HA & Labu \\
\hline N- & Arti \\
\hline NUT-TO-NA & Permisi \\
\hline
\end{tabular}

Perlu diingatkan pada peserta didik bahwa kata pada tipe ini dibaca sebagaimana membaca kata pada tipe ketiga, yakni mengabungkan konsonan dengan vokal, kemudian konsonan dengan konsonan, dan vokal. Setelah itu, ditekankan bahwa ciri akhir ujarannya di silabel pertama diakhiri dengan konsonan dan silabel berikutnya serupa dengan penyebutan di awal pada silabel pertama. Pada tipe ini tidak banyak ditemukan contoh leksikon dalam bahasa Laboya begitu pun yang bertalian dengan budaya Orang Sodan, tetapi ditemukan satu kata yang dapat memunculkan ekspresi dan deskripsi peserta didik terhadap leksikon tersebut, yakni nuttona 'permisi' kata ini tentu memiliki kedekatan denga peserta didik sebab mereka selalu menggunakan kata nuttona sebagai bentuk mohon izin ketika melintas di depan rumah orang lain atau ketika ingin melewati arah orang lain apalagi jika yang dilewati adalah orang tua.

\section{$\mathbf{K V}+\mathbf{K V K}+\mathbf{K V}$}

Merupakan tipe struktur kedelapan dengan tiga silabel.

\begin{tabular}{|l|l|}
\hline H- & Arti \\
\hline HA-KAB-BO & Duduk bercengkrama \\
\hline HA-KAD-DE & Mendirikan \\
\hline HA-RIK-KA & Peralatan tenun \\
\hline K- & Arti \\
\hline KA-BIS-SU & Klan \\
\hline KA-BUK-KU & Bungkuk \\
\hline KA-DAK-TA & Melengket \\
\hline KA-HAB-BA & Ubi jalar \\
\hline T- & Arti \\
\hline TA-GAR-TA & Tergores \\
\hline TA-MEL-HA & Licin \\
\hline TA-WUR-RU & Cincin \\
\hline
\end{tabular}

Dalam mengajarkan tipe ini peserta didik diberikan penjelasan bahwa cara membaca kata pada tipe struktur kedelapan ini dengan menggabungkan konsonan dengan vokal pada suku kata pertama sebagaimana tipe struktur pertama. Kemudian pada suku kata kedua membacanya seperi membaca suku kata pertama pada tipe struktur ketujuh, yakni menggabungkan konsonan dengan vokal, lalu diakhiri dengan konsonan pula. Pada tipe ini tidak banyak ditemukan contoh leksikon dalam bahasa Laboya begitu pun yang bertalian dengan budaya Orang Sodan, tetapi ditemukan beberapa kata yang dapat memunculkan ekspresi dan deskripsi, serta memori kolektif peserta didik terhadap leksikon tersebut. Adapun contoh yang dimaksud, seperti harikka 'komponen alat tenun' kata ini tidak hanya berkesan pada anak perempuan tetapi juga pada anak laki-laki sebab sebelum digunakan oleh perempuan komponen tersebut dibuat oleh laki-laki dari bilah bambu yang diraut seukuran 
jari telunjuk. Bagi perempuan harikka memiliki peranan penting ketika mereka menenun, sebab berfungsi sebagai penahan rangkaian benang, sekaligus pengatur agar tenunan menjadi rapat dan rapi. Berikutnya kabbissu 'klan' ketika membaca kata ini dibenak mereka akan muncul sembilan nama klan yang ada di Kampung Adat Sodan. Selanjutnya kata tersebut membuatnya berpikir atau mengingat tentang sejarah, kekerabatan, rumah adat, dan tugastugas pemimpin tiap klan.

\section{$\mathrm{KV}+\mathrm{KVK}+\mathrm{KV}+\mathrm{KV}$}

Merupakan tipe struktur kesembilan dengan empat silabel.

\begin{tabular}{|l|l|}
\hline H- & Arti \\
\hline HA-LIB-BA-NA & Duduk bersila \\
\hline HA-MIL-LA-KA & Kilat \\
\hline K- & Arti \\
\hline KA-BIS-SU-LA & Bisul \\
\hline KA-LUK-MA-TA & Bulu mata \\
\hline KA-TUP-PA-KA & Dahak \\
\hline M- & Arti \\
\hline MA-YAG-GA-LA & Dingin \\
\hline T- & Arti \\
\hline TA-BIL-LO-KA & Terkilir \\
\hline
\end{tabular}

Dalam mengajarkan tipe ini peserta didik diberikan penjelasan bahwa cara membaca kata pada tipe struktur kesembilan, serupa membaca kata pada tipe struktur kedelapan hanya saja setelah menggabungkan konsonan dengan vokal pada suku kata pertama dan menggabungkan konsonan dengan vokal, lalu diakhiri dengan konsonan pada suku kata kedua, peserta didik harus membaca suka kata berikutnya yang terdiri dari dua bentuk konsonan dan vokal. Pada tipe ini tidak banyak ditemukan leksikon bahasa Laboya begitu pun yang bertalian dengan budaya Orang Sodan, tetapi ditemukan beberapa kata yang cukup akrab dengan mereka, seperti kabissula 'bisul', katuppaka 'dahak', dan tabilloka 'terkilir' ketiga leksikon tersebut dikenali oleh peserta didik sebagai leksikon yang berkaitan dengan sakit dan penyakit.

\section{$\mathbf{K K V}+\mathbf{K V}$}

Merupakan tipe struktur kesepuluh dengan dua silabel, sebenarnya bentuk asli dari tipe ini adalah ${ }^{\mathrm{D}} \mathrm{V}+\mathrm{KV}$.

\begin{tabular}{|l|l|}
\hline NG $(\mathfrak{\eta})$ & Arti \\
\hline NGA-RA & Nama \\
\hline NGA-LA & Ambil \\
\hline NGA-PE & Mencubit \\
\hline NGI-DI & Mengambil \\
\hline NGA-BA & Jurang \\
\hline NGO-YO & Iya \\
\hline NGO-DO & Duduk \\
\hline NGA-HU & Ratusan \\
\hline
\end{tabular}

Dalam mengajarkan tipe ini peserta didik diberikan penjelasan bahwa cara membaca suku kata pertama pada tipe ini adalah dengan mengeluarkan bunyi sengau seperti suara motor. Selanjutnya, mereka diajak untuk latihan menirukan suara tersebut dengan mengucapkan bunyi [ ${ }^{\mathrm{D}}$ / [ng]. Setelah itu, barulah diajarkan bagaimana menggabungkan suku kata pertama dengan suku kata kedua yang terdiri dari konsonan vokal sebagaimana suku kata pada umumnya di beberapa tipe struktur silabel yang dicontohkan sebelumnya. Pada tipe ini tidak banyak ditemukan contoh leksikon dalam bahasa Laboya begitu pun yang bertalian dengan budaya Orang Sodan.

\section{$\mathbf{K V}+\mathbf{V}+\mathbf{K V}(\mathbf{K})+\mathbf{K}(\mathbf{V})$}

Merupakan tipe struktur kesebelas dengan empat silabel.

\begin{tabular}{|l|l|}
\hline B- & Arti \\
\hline BA-U-WIN-NE & Pemudi \\
\hline BA-I-KA-TAR & Ular \\
\hline BA-I-KA-NE-NE & Madu \\
\hline
\end{tabular}


Dalam mengajarkan tipe ini peserta didik diberikan penjelasan bahwa ini merupakan tipe yang terdiri dari empat suku kata sebagaimana tipe struktur kesembilan. Adapun cara membacanya diawali dengan membaca konsonan dengan vokal pada suku kata pertama, kemudian menyebutkan vokal setelah suku kata sebelumnya, lalu membaca atau menggabungkan konsonan dengan vokal, lalu diakhiri dengan konsonan pada suku kata ketiga, terakhir menggabungkan konsonan dengan vokal sebagai suku kata keempat. Hal yang serupa, pada tipe ini juga tidak banyak ditemukan contoh leksikon dalam bahasa Laboya begitu pun yang bertalian dengan budaya Orang Sodan.

\section{PENUTUP}

Mengajarkan baca tulis tidak hanya sebatas penggunaan bahasa ibu atau dialek setempat sebagai pengantar dalam pembelajaran, tetapi perlu menggunakan materi ajar yang berasal dari bahasa ibu mereka sehingga bukan hanya kemudahan peserta didik dalam memahami materi ajar yang terlihat, tetapi kebanggan terhadap identitas juga tumbuh di antara mereka sebab mereka melihat ada apresiasi terhadap bahasa ibunya.

Distribusi kosakata bahasa Laboya pada 11 tipe silabis yang ditampilkan, sebenarnya belum merata, sejauh ini penulis belum menemukan jumlah kosakata berdasarkan urutan abjad yang sepadan pada masing-masing tipe sebagaimana bahasa Indonesia. Begitu juga dengan leksikon bahasa Laboya yang bertalian dengan budaya Orang Sodan pun distribusinya tidak merata pada sebelas struktur silabis yang ditampilkan. Meskipun demikian setidaknya terdapat beberapa contoh leksikon yang tidak hanya memunculkan ekspresi dan deskripsi, tetapi juga memori kolektif mereka yang tidak dapat ditemukan di luar bahasa Laboya. Semoga penelitian ini terus berlanjut hingga menemukan bentuk yang ideal sesuai yang diharapkan, terkait materi ajar berbasis bahasa Ibu, baik pada bahasa Laboya sendiri maupun bahasa ibu lainnya.

\section{DAFTAR PUSTAKA}

ACDP. (2014). Pendidikan Multi Bahasa Berbasis Bahasa Ibu. Jakarta: ACDP Indonesia.

Anindita, A. D. (2019). Melawan Setan Bermata Runcing: Pengalaman Gerakan Pendidikan Sokola. Jakarta: Sokola Institute.

Aritonang, B. dkk. (2002). Kosakata Dasar Swadesh di Sumba Barat, Sumba Timur, dan Timor Tengah Utara. Jakarta: Pusat Bahasa Departemen Pendidikan Nasional.

Badan Pengembangan dan Pembinaan Bahasa. (2017). Bahasa dan Peta Bahasa di Indonesia. Jakarta: Kementrian Pendidikan dan Kebudayaan.

Dewi \& Antosa, Z. (2020). Kemampuan Literasi Dasar Melalui Gerakan Literasi Dasar Sekolah (GLS) di SDN 6 Pekanbaru. Jurnal Pajar (Pendidikan dan Pengajaran), 499-505.

Ghanggo Ate, Y. (2019). Pengajaran Literasi Berbasis Bahasa Ibu: Suatu Alternatif Menguarai Isu Literasi di Sumba. Makalah Orasi Ilmiah Wisuda Perdana STKIP Weetebula, 2. 
Hanemann, U. (2005). Literacy For Special Target Groups: Indigenous Peoples. Education for All Global Monitoring Report, 9-10.

Ibda, H. (2017). Urgensi Pemertahanan Bahasa Ibu di Sokolah Dasar. Jurnal Shahih, 199.

Inovasi. (2019). Laporan Baseline Sumba Barat Nusa Tenggara Timur. Jakarta: INOVASIInovasi Untuk Anak Sekolah Indonesia.

Kemendikbud. (2019). Penduduk Buta Aksara Tahun 2018. Jakarta: Kementrian Pendidikan dan Kebudayaan.

Lopez, L. E. (2000). Intercultural Bilingual Education in Latin America: $\quad$ Cochabamba: PROEIB Andes.

Mahsun. (2001). Peran Bahasa Ibu dalam Membangun Kebudayaan Daerah. Makalah disajikan dalam Musakarah Reaq Adat Tanaq Samawa, pada tanggal 25-26 Oktober 2001. Hal.: 1-19.
Moleong, L. J. (2017). Metode Penelitian Kualitatif. Bandung: Rosda.

Rizaty, M. A. (2021, Juni 23). databoks. Retrieved from databoks.katadata.co.id: https://databoks.katadata.co.id/ datapublish/2021/06/23/angkabuta-huruf-di-indonesiacenderung-menurun-dalamsatu-dekade\#

Saryono, D., \& dkk. (2017). Materi Pendukung Literasi Baca Tulis. Jakarta: Kementerian Pendidikan dan Kebudayaan.

Spain, U. a. (1994). The Salamanca Statement and Framework for Action On Special Needs Education. Salamanca, Spain: UNESCO.

Verdizade, A. (2019). Selected Topics in The Phonology and Morphosyntax of Laboya. Stockholm: $\quad$ Stockholm University.

Yogaswara, H., \& Zamjani, I. (2019). Pendidikan Kontekstual Masyarakat Adat di Indonesia . Jakarta: Kementrian Pendidikan dan Kebudayaan. 